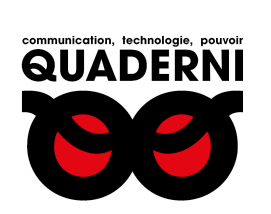

\title{
Quaderni
}

Communication, technologies, pouvoir

103 | Printemps 2021

Les ruses du hacking

\section{Hacking, la nouvelle ruse activiste}

\section{Emmanuel Täieb et Étienne Candel}

\section{(2) OpenEdition}

\section{Journals}

\section{Édition électronique}

URL : https://journals.openedition.org/quaderni/1960

DOI : 10.4000/quaderni.1960

ISSN : 2105-2956

\section{Éditeur}

Les éditions de la Maison des sciences de l'Homme

Édition imprimée

Date de publication : 15 juin 2021

Pagination : 5-7

\section{Référence électronique}

Emmanuel Taïeb et Étienne Candel, « Hacking, la nouvelle ruse activiste», Quaderni [En ligne], 103।

Printemps 2021, mis en ligne le 15 juin 2021, consulté le 07 octobre 2021. URL : http://

journals.openedition.org/quaderni/1960; DOI : https://doi.org/10.4000/quaderni.1960 


\section{Éditorial: Hacking, \\ la nouvelle ruse activiste}

\section{Emmanuel Taïeb}

Sciences Po Lyon (Triangle)

\section{Étienne Candel}

Université de Paris (CERLIS) 
Sous une forme "numérique" se jouent à bas bruit depuis longtemps des guerres dont les citoyens des États démocratiques n'ont pas toujours une conscience claire. Cyberoffensives, attaques par déni de service, blocages de sites, piratages de serveurs, vols de données, sans oublier du côté de l'information de nouvelles formes de propagande et d'intox, qui font douter des vérités scientifiques les plus ancrées et alimentent le complotisme et la machine à outrances incontrôlables des réseaux sociaux. Sur ce front numérique se retrouvent des individus, des groupes de hackers, d'informaticiens hors du commun, mais aussi les États qui parfois les emploient.

Même en temps de paix les pays rivaux se livrent donc une guerre permanente, une "compétition stratégique" destinée à déstabiliser l'adversaire, mais sans que les canons tonnent. Une compétition qui ne doit pas faire de morts, mais qui n'est pas non plus purement symbolique. L'arme favorite est celle de la désinformation, phénomène que les réseaux sociaux numériques ont doté d'une résonance sans précédent et d'une échelle internationale inédite. Car après tout les fausses nouvelles sont un phénomène ancien. L'historien Marc Bloch y avait déjà consacré un ouvrage au sortir de la Première Guerre mondiale, pour montrer à quel point le flottement de l'information avait pu être déstabilisant pour les combattants. Cent ans plus tard, l'intoxication de l'ennemi ne s'est jamais aussi bien portée que dans le contexte numérique. Sauf que désormais la propagande ne vise plus à influencer sa propre population, mais celle d'un autre pays. Il y a bien eu une ingérence russe dans les élections américaines de 2016, et un an plus tard, les "MacronLeaks", un peu oubliés aujourd'hui, marquaient la tentative de saboter de l'extérieur le processus démocratique français, pour vraisemblablement faire gagner Marine Le Pen.

L'usage du numérique comme arme de guerre est donc pris au sérieux par les États, qui ont tous lancé des services de surveillance, de protection de leurs réseaux et de contre-information pour ne pas laisser s'installer en interne le discours saboteur de l'autre'. Cet arsenal sert aussi à lutter en ligne contre le djihadisme ${ }^{2}$, redoublant les opérations extérieures des armées, sur lesquelles plane en permanence le risque de l'enlisement, des pertes humaines et des critiques de l'opinion publique.

Ouvrir un front numérique et s'adjoindre les services de hackers permet de s'exposer différemment, de ruser avec un ennemi plus fort en employant des moyens silencieux et invisibles, voire "déloyaux" mais légitimes, dont les dégâts peuvent être importants. Le hacking, c'est Machiavel au clavier. La tâche demeure cependant complexe, car les serveurs, les moyens d'accès, et les réseaux sociaux sont

1. Céline Marangé, Maud Quessard (dir.), Les guerres de l'information à l'ère numérique, Paris, Puf, 2021.

2. Marc Hecker, Elie Tenenbaum, La Guerre de vingt ans. Djihadisme et contreterrorisme au XXIe siècle, Paris, Robert Laffont, 2021. 
détenus par des groupes privés, plus ou moins coopératifs. Surtout, les catégories sont labiles. Le "hacker" des discours contemporains n'est plus seulement le nerd du film WarGames (1983), pirate capable de s'introduire dans les systèmes informatiques les plus complexes, ni non plus le geek qui depuis son garage peut modifier le cours des choses sur toute la planète. C'est peut-être déjà davantage Lisbeth Salander dans Millenium. À la fois auxiliaire de l'enquêteur et guerrière engagée - en l'occurrence, féministe.

Le hacker peut aussi être militant et défendre des causes politiques, plaidant, comme insider informé, pour la responsabilité dans l'utilisation de ce qui relève de la vie privée, pour les libertés publiques, pour une participation citoyenne accrue, et luttant contre les usages commerciaux ou liberticides des données personnelles. La démocratisation d'Internet, la mise à disposition d'outils pour chacun, leur gratuité et leur utilisation intuitive, peuvent transformer chacun en hacker, moyennant une petite expertise. C'est donc que la catégorie est moins importante que l'action elle-même. Le "hacking", ou plus précisément l'"hacktivisme" (néologisme obtenu par haplologie entre "hacker" et "activisme"), apparaît maintenant comme une nouvelle série de formes inscrites au répertoire de l'action collective, novatrices et faisant feu de tous les outils informatiques disponibles, sans truchement d'organisations partisanes ou syndicales jugées obsolètes, et de façon géographiquement éclatée et déterritorialisée. Le hacking dans ce cadre dit bien la mondialisation des flux d'informations et la capacité de projection au-delà de toute frontière nationale. Il dit aussi la fragilité des pays face à une gestion des flux d'information et de données qui peuvent facilement leur échapper, quand ils ne les contrôlent pas en amont, sur les modèles chinois et russes.

Qu'ils soient créateurs de richesse, affiliés aux États ou journalistes luttant au contraire contre un régime illibéral, lanceurs d'alerte ou groupes malveillants, ou encore Anonymous justiciers que dans tous les cas les États essaient de faire taire, les acteurs du hacking examinés dans ce numéro organisent la résistance à la société de contrôle, contournent les censures, et d'une façon générale inventent des pratiques numériques protestataires et rebelles d'un nouveau type. Et si la reconquête démocratique passait finalement par l'activisme numérique? 
